\title{
In Reference to the Article A Comparative Study Between Endoscopic Middle Meatal Antrostomy and Caldwell-Luc Surgery in the Treatment of Chronic Maxillary Sinusitis
}

\author{
By K. Joe Jacob · Shibu George · S. Preethi · V. S. Arunraj
}

\author{
Sashikanth Jonnalagadda
}

Received: 8 September 2011 / Accepted: 14 September 2011/Published online: 27 September 2011

(C) Association of Otolaryngologists of India 2011

\section{Dear Editor}

I read with grave concern the article by K. Joe Jacob et al. discussing the comparative efficacy and complications of endoscopic sinus surgery and Caldwell-Luc in the treatment of chronic sinusitis. As rightly noted by authors themselves Caldwell-Luc is fairly abandoned in the treatment of chronic sinusitis for various reasons including-(a) Increased incidence of complications when compared to endoscopic sinus surgeries [1], (b) decreased cure rates when compared to endoscopic sinus surgeries [2]. Endoscopic sinus surgery is more physiological because it adheres to the principles of mucosal clearance and hence mucosal preservation is emphasized. The complications and morbidity associated with Caldwell-Luc range for 10-40\% [3].Hence endoscopic sinus surgery is now the 'standard of care' worldwide for the management of chronic sinusitis.

Now this raises an ethical question in the study design used by the authors. When endoscopic sinus surgery is available at the authors disposition, offering Caldwell-Luc as a treatment option to the patients is unethical as there is considerable evidence in literature already showing increased morbidity and decreased efficacy of Caldwell-Luc when compared to endoscopic sinus surgery. If a true informed consent was obtained explaining the risks, benefits and the outcomes of both treatment options, it is very difficult to understand how a consent for Caldwell-Luc could be obtained. The authors findings are definitely valid, but similar findings have been demonstrated more than a decade and half earlier $[1,2]$ and this study is like "reinventing the wheel" at the expense of patients who did not receive the 'standard of care' even when that was available. The authors should have done a thorough review of literature before conducting a study when considerable morbidity is associated with one treatment option compared to the other. There appears no need to conduct prospective randomized comparative study when the benefit of one option both in terms of increased efficacy and decreased complications appear overwhelming clear [4]. The authors could just have compared their results from endoscopic sinus surgery with results of Caldwell-Luc surgery already found in literature.

\section{References}

1. Ikeda K, Hirano K, Oshima T, Shimomura A, Suzuki H, Sunose H et al (1996) Comparison of complications between endoscopic sinus surgery and Caldwell-Luc operation. Tohoku J Experim Med 180(1):27-31

2. Penttilä MA, Rautiainen ME, Pukander JS, Karma PH (1994) Endoscopic versus Caldwell-Luc approach in chronic maxillary sinusitis: comparison of symptoms at one-year follow-up. Rhinology 32(4):161-165

3. DeFreitas J, Lucente FE (1988) The Caldwell-Luc procedure: institutional review of 670 cases: 1975-1985. The Laryngoscope 98(12):1297-1300

4. Smith GCS, Pell JP (2003) Parachute use to prevent death and major trauma related to gravitational challenge: systematic review of randomised controlled trials. Br Med J 327(7429):1459-1461

\footnotetext{
S. Jonnalagadda $(\bowtie)$

Department of Otolaryngology-Head and Neck Surgery,

SIU School of Medicine, Springfield, IL 62702, USA

e-mail: sjonnalagadda@ siumed.edu
} 